\title{
Learning Third Language Brings Changes in Executive Function: An ERP Study ${ }^{*}$
}

\author{
Young Hye Kwon \\ (Seoul National University \& \\ Korea Advanced Institute of Science and Technology) \\ Sung-Eun Lee \\ (Seoul National University)
}

\begin{abstract}
Kwon, Young Hye and Lee, Sung-Eun. (2017). Learning Third Language Brings Changes in Executive Function: An ERP Study. Language Research, 53.3, 445-471.
\end{abstract}

\begin{abstract}
A number of studies have found that bilinguals differ from monolinguals not only in verbal aspects but also in nonverbal cognitive functions. This study aims to investigate whether learning a third language also affects our executive functions. To demonstrate a direct effect of learning a third language (German) in executive function, 32 English-Korean bilinguals participated in the ERP experiments twice: before and after language training. Based on the Dual Mechanism Control (DMC) model, we used an AX-CPT paradigm to analyze the proactive control processing with $\mathrm{P} 3 \mathrm{~b}$ and reactive control processing with N2 and P3a components. The results showed an increase in P3a amplitudes after learning the third language which implies enhanced response inhibitory function. Thus, our results suggest not only the second language but also the third language acquisition influences reactive control functions.
\end{abstract}

Keywords: multilingualism, executive function, AX-CPT, ERP, P3a, P3b, N2

\section{Introduction}

Ability to use more than one language, called "multilingualism," is becoming more important in today's society not only for communicating

* This work was supported by Promising-Pioneering Researcher Program through Seoul National University (SNU) in 2015. 
with each other but also for social and economic advantages (Aronin and Singleton 2008; Guo et al. 2013). This phenomenon encourages people, from the young to the old, to learn new languages in addition to their native languages (Cenoz 2013).

In keeping with these changes around the world, numerous studies have focused on the linguistic effects of multilingualism asking how these multiple languages are processed in the brain. These verbal impacts have been observed from phonology to syntax and from children to adults (Kaushanskaya and Marian 2009; Moreno et al. 2010; Rubin and Turner 1989). Moreover, recent studies have found that multilingualism also affects nonverbal cognitive functions, specifically the executive function which includes goal activation, conflict detection, inhibit distraction, attention, planning, decision making, and other cognitive functions (Bialystok 2001, 2010; Bialystok and Martin 2004; Braver et al. 2002; Carter and Van Veen 2007; Emmorey et al. 2008; Martin-Rhee and Bialystok 2008; Miyake et al. 2000; Poarch and van Hell 2012). Many studies have found the better executive function performance in multilinguals compared to monolinguals, and this is due to a characteristic of language processing that multilinguals have. When multilinguals choose one language to use, all acquired languages activate simultaneously in their brains. This "parallel activation" of languages requires multilinguals to choose and maintain one language, and at the same time, suppress other languages to engage in successful communication (Spivey and Marian 1999; Van Heuven et al. 1998). This parallel activation leads multilinguals to use the executive function continuously and it eventually enhances executive function, which is known as a "multilingual advantage" (Dijkstra and van Heuven 1998; Gollan and Kroll 2001; Green 1998; Levy et al. 2007; Meuter and Allport 1999). This multilingual advantage has been reported in a number of previous studies with subjects from children to adults (Bialystok and Martin 2004; Emmorey et al. 2008; Martin-Rhee and Bialystok 2008; Morales et al. 2013; Poarch and van Hell 2012). For example, Bialystok and Martin (2004) investigated whether multilingual children have better executive function than their monolingual peers. They used a dimensional-change card-sort task that requires inhibition control 
to conduct the task accurately, and the result showed that the multilingual group outperformed the monolingual group. This result demonstrates the better inhibition control function of the group with more than one language. A study by Poarch and van Hell (2012) compared monolinguals, second language learner, bilinguals, and trilinguals using Simon task and attentional networks task. The result found better inhibition and conflict detection function in multilinguals than monolinguals. This study suggests an important implication that the cognitive advantage is not limited to two languages but also well applied to additional languages.

The previous studies have found that language acquisition enhances executive function regardless of the participant's age, but the majority of previous studies have focused on only one or two executive functions with individual tasks (for review see Valian 2014). However, to engage in successful multilingual communications, an interplay of several functions, choosing and maintaining a selected language while inhibiting other languages, is required. Therefore, not only how these executive functions work individually but also a model which explains how they cooperate with each other when multilinguals use their languages is strongly needed to explore the language learning effect in multilinguals, and this can be well explained by a dual-mechanism control (DMC) model. The key hypothesis of this model is that the cognitive function is a combination of two different processes, a "proactive control process" and a "reactive control process" (Braver 2007). The proactive control process actively maintains goal-related information until a cognitively demanding event occurs. In contrast, the reactive control process concentrates attention after a burden event occurs. The DMC model insists that these two cognitive control processes must work together to achieve a goal successfully. This model can be applied to language processing in multilinguals because proactive control, which is an anticipating and preparing process for an event, is needed for the use of ongoing language, and reactive control, which is a detecting and resolving process, is required in order to shift from and inhibit other languages.

An adequate task that represents the DMC model best is an $\mathrm{AX}$ version of the continuous performance task (AX-CPT) because it can measure 
both the proactive and reactive control processes simultaneously (Braver 2012). This paradigm has been used in many studies and in diverse fields that investigate executive functions (Kam et al. 2012; Lamm et al. 2013; Morales et al. 2013; van Wouwe et al. 2010; Zhang et al. 2015). The AX-CPT paradigm asks participants to look at two letters that appear one by one in the middle of the screen and to press a button depending on four conditions. Participants have to press the "yes" button only if the first cue letter " $\mathrm{A}$ " precedes the second probe letter " $\mathrm{X}$ " (A-X condition), and in all the other three conditions, participants have to press "no": A-cue and non-A-probe (A-Y condition), non-A-cue and X-probe (B-X condition), and non-A-cue and non-X-probe (B-Y condition). Since the A-X condition is a target condition that constitutes $70 \%$ of the total stimuli and the remaining three conditions constitute the remaining $30 \%$ ( $10 \%$ each), this uneven stimulus presentation ratio leads to a biased response in every condition, which allows us to measure both proactive and reactive control processing.

In AX-CPT paradigm, the conditions of $\mathrm{A}-\mathrm{Y}$ and $\mathrm{B}-\mathrm{X}$ are the key conditions. Whereas A-X condition is a target condition and B-Y condition is considered as a baseline condition, the A-Y condition requires both reactive and proactive controls, but $\mathrm{B}-\mathrm{X}$ condition relies more on reactive controls and less on proactive control. The cue " $\mathrm{A}$ " encourages the participants to prepare the reaction for the upcoming target probe " $\mathrm{X}$ " because of their large number of trials, which is a proactive control, but when unexpected probe "Y" appears on the screen, the participants have to suppress their prepared reaction which is now a reactive control. In contrast, B-X condition is mainly processed using reactive inhibition control and uses less proactive control. Since the cue " $B$ " informs the participants that this trial cannot be a target trial, they do not rely on their proactive controls. However, when probe " $\mathrm{X}$ " appears on the screen, the participants have to inhibit their habituated reaction which is pressing the "yes" button on probe "X."

The goal of our study is to investigate the effect of the third language learning using the AX-CPT paradigm that allows us to observe how the third language gives changes to our executive functions. Moreover, be- 
cause these executive functions and language processing are very immediate processes, event-related potential (ERP) can be an ideal neurophysiological method in terms of being a direct measurement of neuronal activities, non-invasiveness, and a great temporal resolution of milliseconds (Kim \& Osterhout 2004). ERP is extensively used in various research fields, including studies of language learning effects which have proven that cognitive functions change as a result of new language learning (Kuipers et al. 2017).

The ERP components of P3b, N2, and P3a can be important indexes for measuring executive functions in the AX-CPT paradigm (Figure 1). $\mathrm{P} 3 \mathrm{~b}$ is a positive-going ERP component that has its peak around 250-600 $\mathrm{ms}$ after the onset of a stimulus. The exact location of the $\mathrm{P} 3 \mathrm{~b}$ is not known yet, but the Pz electrode has been reported as the main site (Polich 2003, 2007). According to Polich (2007), P3b is observed during the processes of executive functions, such as context updating, goal activation, working memory, and attention. In AX-CPT, goal activation when a cue letter appears induces $\mathrm{P} 3 \mathrm{~b}$ because it requires a participant to prepare for the response, which is a proactive control process. $\mathrm{P} 3 \mathrm{~b}$ tends to have a larger amplitude in the B-cue condition than in the A-cue condition. The reason for this tendency is that B-cue, which constitutes only $20 \%$ of the total stimulus, requires stronger goal activation setting than the A-cue, and it has been proven in many previous studies to be an indicator of the proactive control process (Gratton et al. 1990; Morales et al. 2015; Ruchkin et al. 1995; Wright et al. 2002).

$\mathrm{N} 2$ is a negative-going wave that has its peak around $250-350 \mathrm{~ms}$ after the onset of a stimulus, and it is mostly found at the location of $\mathrm{Fz}$ or FCz (Folstein and Van Petten 2008). In the past, N2 has been known to play a suppression function, but recently it has been interpreted as representing a conflict detection rather than inhibition function (Falkenstein 2006; Folstein and van Petten 2008; Nieuwenhuis et al. 2003; Van Veen 2002). The N2 peak is observed when the conflict is detected, such as when a target-unrelated stimulus appears during the experiment. In the AX-CPT, N2 is one of the indicators that reflect the reactive control process. In particular, this component is most pronounced in the A-Y 
condition because the expectancy of probe $\mathrm{X}$ when cue A appears on the screen makes participants detect $\mathrm{Y}$ as a conflict. Many studies have confirmed $\mathrm{N} 2$ in the A-Y condition to be an indicator of the reactive control process (Hammerer et al. 2010; Mazza et al. 2009; van Wouse et al. 2010).

$\mathrm{P} 3 \mathrm{a}$ is a positive-going ERP component that is observed at $\mathrm{Fz}$ or $\mathrm{Cz}$ electrode sites. It has its peak latency between $250-500 \mathrm{~ms}$ after a stimulus presentation (Näätänen 2014). Unlike the goal activation component P3b, $\mathrm{P} 3 \mathrm{a}$ is a component of the reactive control process that reflects the ability to inhibit the response to a given disturbance stimulus (Goldstein et al. 2002). In general, $\mathrm{P} 3 \mathrm{a}$ is observed in both the A-Y and $\mathrm{B}-\mathrm{X}$ conditions but is larger in the A-Y condition because an unexpected Y-probe makes participants suppress their prepared response to the expected X-probe (Kam et al. 2012; Sullivan et al. 2014). Therefore, larger P3a in the A-Y condition implies that the reactive control process has normally been activated (Morales et al. 2015).

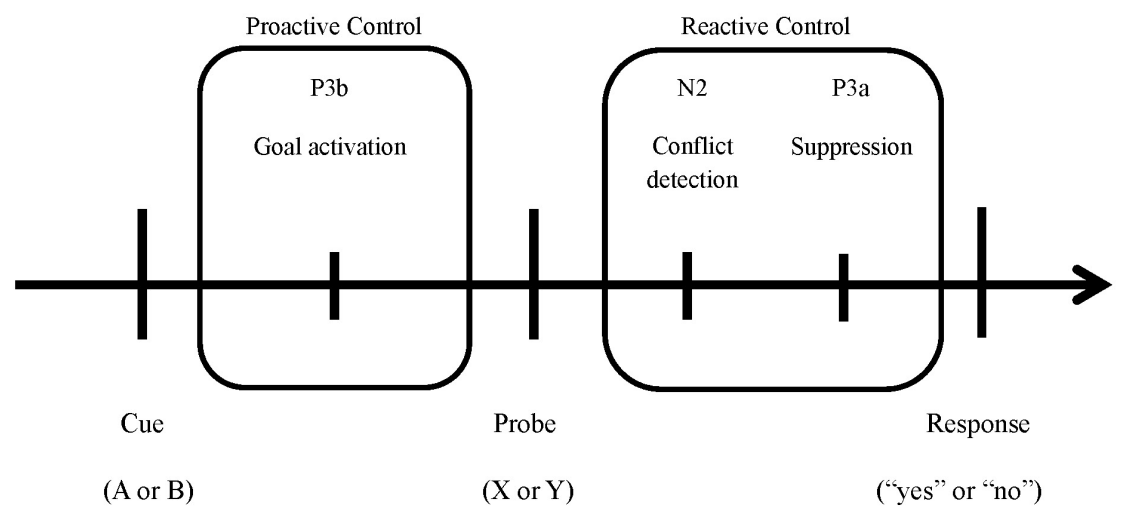

Figure 1. ERP components associated with AX-CPT paradigm (This figure is based on work by Morales et al. 2015).

In the study by Sullivan et al. (2014), a group of native speakers of English performed a go/nogo task while recording EEG, before and after the 6 months of Spanish learning. As a result, the ERP component P3 increased after the second language learning, but N2 did not change. One previous study investigated the difference in executive functions between 
monolinguals and bilinguals using the AX-CPT (Morales et al. 2015). They used the ERP components of P3b, N2, and P3a as indexes for task goal activation, conflict detection, and response inhibition, respectively. The results showed that bilinguals did not differ from monolinguals in $\mathrm{P} 3 \mathrm{~b}$, but bilinguals showed a larger $\mathrm{P} 3 \mathrm{a}$ component in AY and BY conditions and more negative N2 component in AY condition than monolinguals. In other words, bilinguals did not differ from monolinguals on proactive control but showed higher reactive control compared to monolinguals. With reference to this study, we aimed to explore whether the third language acquisition also brings multilingual advantages.

In this study, we aimed to investigate multilingual advantages in terms of the learning of a third language using ERP with the AX-CPT paradigm. Our research revolved around discovering whether multilingual advantage would be enhanced, reduced, or maintained when bilinguals learn an additional language. We hypothesized that learning a third, additional language would bring changes, not only to the language skill itself, but would also enhance executive functions such as goal activation, conflict monitoring, and response inhibition, because of more the frequent use of these controls in order to successfully manage the languages in parallel activation. We compared our participants' ERP activities twice, before and after the third language learning which allowed us to observe the direct effects of the third language learning on the executive functions. This learning paradigm overcame the limitations of previous studies which only showed an indirect effect of multi-language acquisition by researching subjects who had already acquired the language. Moreover, this research aims to study the effects of third language learning on executive function; a topic that, despite being increasingly significant, still lacks proper research questions on multilingualism. We expect that cognitive controls like goal activation, conflict monitoring, and inhibition will be enhanced after bilinguals learn an additional language. 


\section{Method}

\subsection{Participants}

Thirty-two Seoul National University, South Korea, undergraduate students between ages of 18 and 27 years old participated in the experiment. All participants were bilinguals having Korean as their first language (L1) and English as their second language (L2). According to Mackey (1987), we defined a bilingual as a person who has knowledge of two or more languages and who knows how to use them. The learning group consisted of sixteen students who registered for 'Elementary German 1' in the fall semester, held at the Department of German Language and Literature at Seoul National University (six females, mean age $=19.63, \mathrm{SD}=2.03$ ). The participants of the learning group were selected on the basis of self-reports. Any participant who violated the standards and policies of the study was excluded from the experiment. The selected participants reported that they had never studied German or other foreign languages other than English before, and those who had studied a foreign language in the past reported that they cannot remember the language they had learned. Students in the class should take three hours of lecture and one hour of lab class per week, and this curriculum lasted for six weeks. Therefore, all students took 18 hours of lecture and six hours of lab class for the experiment. In the lab class, students encouraged to communicate with classmates and native German teachers to improve their communication skills in a more natural environment. Through this course taking, participants in learning group could be controlled based on the same curriculum and same study materials. All participants attended every lecture and finished all of the given assignments. A control group was recruited for the purpose of eliminating any possibilities of practice effect of the paradigm. Sixteen students in the control group were from the same university who did not register for any language courses, and they did not have any plans to study language alone during the period (seven females, mean age $=22.82, \mathrm{SD}=2.43$ ). All participants in the control group reported that they do not have any history of learning foreign languages other than English before, and who had studied a foreign language in 
the past reported that they hardly remember the learned language. No participants had histories of visual and auditory dysfunctions and psychological treatment.

To eliminate the L2 proficiency effect, we recruited the participants firstly based on the test of English proficiency (TEPS) score which is developed by Seoul National University and then controlled them again based on the self- reporting score and bilingual switching questionnaire (BSWQ). The analysis revealed no differences in TEPS scores between learning and control groups $(t(30)=-1.387, p=.176)$.

All participants were asked to self-rate their second language (English) proficiency. Based on their language history, they rated the second language proficiency from 1 (very poor) to 7 (native-like) in reading, writing, speaking, and listening domains ( $\mathrm{Li}$ et al. 2006). The analysis showed learning and control groups had equivalent L2 proficiency (reading: $t(30)$ $=-.440, p=.663$; writing: $t(30)=0.178, p=.860$; speaking: $t(30)=$ $.914, p=.368$; listening: $t(30)=1.447, p=.158)$.

Language switching questionnaire consists of 12 questionnaires, and participants were asked to self-rate the tendency of switching languages between L1 (Korean) and L2 (English) (Rodriguez-Fornells et al. 2011). The questionnaires are divided into four sections; (1) SWL1: the tendency that language users switch their L2 (English) to L1 (Korean) (e.g., "When I cannot find a word in English, I tend to immediately produce it in Korean"), (2) SWL2: the tendency that language users switch their L1 (Korean) to L2 (English) (e.g., "When I cannot find a word in Korean, I tend to immediately produce it in English"), (3) CS: contextual switching, an index that how language users frequently switch between their two languages depend on a particular condition or circumstance (e.g., "There are situations in which I always switch between the two languages), (4) US: unintended switching, a measurement of language switching that language users shift their languages without intention or awareness (e.g., "It is difficult for me to control the language switches I introduce during a conversation) (Table 1). No differences were found in any of these questionnaires between learning and control groups (SWL1: $t(30)=0.141$, $p=.889$; SWL2: $t(30)=0.112, p=.912$; CS: $t(30)=0.745, p=.462$; 
US: $t(30)=0.691, p=.495)$.

Since the goal of this study is to compare cognitive functions before and after acquiring the third language, general intelligence and working memory capacity are the important factors to be controlled. To control these factors, all participants performed IQ and working memory task.

All participants had online Raven's advanced progressive matrices (RAPM) to test their intelligence quotients (www.iqtest.dk, Version3.0). RAPM measures an abstract reasoning cognitive function ruling out the possibilities that may come from language ability or cultural differences (Raven 2003). No differences were found between learning and control groups $(t(30)=1.164, p=.253)$.

Computer-based operation span task (Ospan; www.milliseceond.com, Version 4.0.9.0) was conducted for all participants. In this task, participants had to do mental arithmetic to solve simple arithmetic problems while maintaining lists of alphabets in mind. One calculation is followed by one letter, and this rotation may be repeated up to 7 times per session. End of each session, participants had to recall all the alphabets in order of the presence. The t-test shows no working memory capacity differences between two groups (total working memory: $t(30)=1.258, p=.218$; total correct letter: $t(30)=1.457, p=.156$; total math error: $t(30)=-1.137$, $p=.265$; math speed error: $t(30)=-.604, p=.550$; math accuracy error: $t(30)=-.804, p=.428)($ Table 1$)$.

Table 1. Average Scores and Standard Deviations for IQ, Working Memory Task (Ospan Task), L2 Proficiency Tests (TEPS, Self-report, BSWQ) by Groups

\begin{tabular}{lcc}
\hline & Learning group & Control group \\
\hline \hline $\mathrm{N}$ & 16 & 16 \\
\hline $\mathrm{Ige}$ & $19.63(2.03)$ & $22.82(2.43)$ \\
\hline Ospan & $126.5(10.92)$ & $122(10.94)$ \\
\hline Total working memory score & $54.188(11.69)$ & $49.14(10.06)$ \\
\hline Total correct letter score & $68.188(4.85)$ & $65.286(6.06)$ \\
\hline Total math error score & $2.563(1.32)$ & $3.429(2.71)$ \\
\hline
\end{tabular}




\begin{tabular}{lcc}
\hline & Learning group & Control group \\
\hline \hline Math speed error & $1.0(.97)$ & $1.214(.98)$ \\
\hline Math accuracy error & $1.688(1.14)$ & $2.214(2.33)$ \\
\hline L2 proficiency & & \\
\hline TEPS & $681.56(117.35)$ & $742.75(128.19)$ \\
\hline Self-report (1-7 point) & & \\
\hline Reading & $5.06(1.00)$ & $5.19(.54)$ \\
\hline Writing & $4.25(.77)$ & $4.19(1.17)$ \\
\hline Speaking & $3.94(1.39)$ & $3.50(1.32)$ \\
\hline Listening & $5.25(1.29)$ & $4.63(1.15)$ \\
\hline BSWQ (1-15 point) & & \\
\hline SWL1 & $10.53(2.31)$ & $9.87(3.44)$ \\
\hline SWL2 & $12.13(2.61)$ & $11.53(2.08)$ \\
\hline CS & $8.0(.72)$ & $6.47(.70)$ \\
\hline US & $9.2(4.47)$ & $7.2(3.14)$ \\
\hline
\end{tabular}

SWL1: switch to L1, SWL2: switch to L2, CS: contextual switching, US: unintended switching.

\subsection{Materials}

The participants were asked to press keyboards after watching two capital letters (cue and probe) which present one at a time in the middle of the screen while recording EEG. Every event starts with a fixation mark "+" which lasts for 200 ms followed by the first alphabet (cue) and the second alphabet (probe). Each stimulus was presented for 250 $\mathrm{ms}$, the interstimulus interval (ISI) was $2000 \mathrm{~ms}$, and the intertrial interval (ITI) was $1000 \mathrm{~ms}$ (Figure 2). Participants were asked to press "J" button on a keyboard with their right index finger when the first cue alphabet " $\mathrm{A}$ " precedes the second probe alphabet " $\mathrm{X}$ " (A-X condition). If the cue-probe pair is not the A-X condition, the participants were asked to press " $F$ " key with their left index finger.

\subsubsection{Stimuli and procedure}

Total four conditions were used in the AX-CPT task; cue alphabet of " $A$ " followed by a probe alphabet "X" (A-X), cue " $A$ " followed by 
a probe "non-A" (A-Y), cue "non-A" followed by a probe "X" (B-X), and "non- $A$ " cue followed by a "non- $X$ " probe (B-Y). Among these four conditions, the target condition "A-X" takes $70 \%$ of the whole stimuli and the rest of three conditions constitute the remaining 30\%.

Participants will set a goal to press "yes" button when the A-cue appears. Likewise, when B-cue presents, participants will prepare to press "no" button regardless of the next probe alphabet. This preparing and setting a goal can be considered as a proactive control process of the DCM model. Also, if the probe alphabet after A-cue is an alphabet other than X (A-Y condition), participants have to press "no" button instead of the "yes" button, which is a biased response resulting from a high percentage of the A-X condition. In B-X condition, even though the cue is not $\mathrm{A}$, the $\mathrm{X}$-probe induces biased "yes" response because of its high occurrence. These responses correspond to the reactive control process of the DCM model.

Thus, both A-Y condition and B-X condition require reactive control processes, but A-Y condition requires an additional proactive control process, maintaining goal activation. In other words, A-Y condition represents the reactive control with the proactive process, while the $\mathrm{B}-\mathrm{X}$ condition reflects only the reactive control.

Participants had ten practice trials before starting the main task, and whoever did not get used to the task paradigm were allowed to repeat the practice trials until they fully understand the task. All subjects participated the experiment twice at an interval of six weeks (mean days = $39.13, \mathrm{SD}=4.61$ ). The experiment consists of two sessions with 150 trials each. Each EEG experiment lasted around one and a half hours including set up and experiment time. The stimulus was showed with 72 points for the alphabet and 45 points for the fixation marks, and they appeared in the center of the screen in a white bolded Arial Black font against a black background using E-Prime 2.0 software (Schneider et al. 2012). 


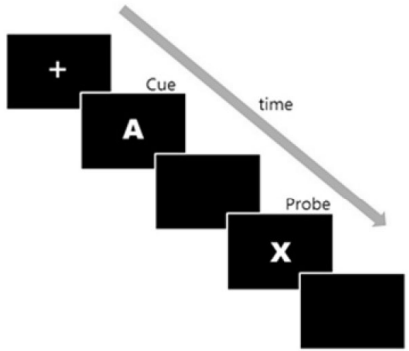

A- $X$ condition(target trial), $70 \%$ cue: $A$, probe: $X$

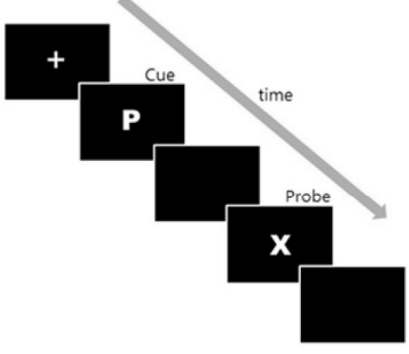

B- $X$ condition, $10 \%$ cue: non-A, probe: $X$

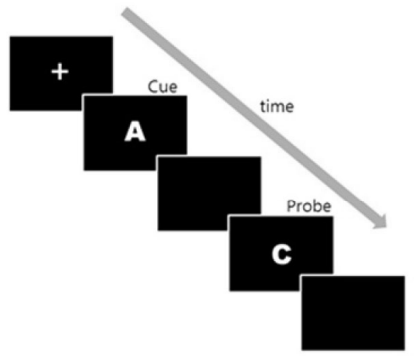

A-Y condition, $10 \%$ cue: $A$, probe: non-X

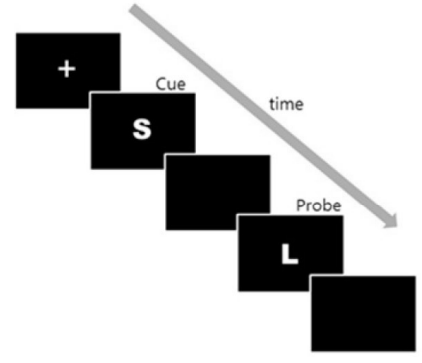

B-Y condition, $10 \%$ cue: non-A, probe: non-X

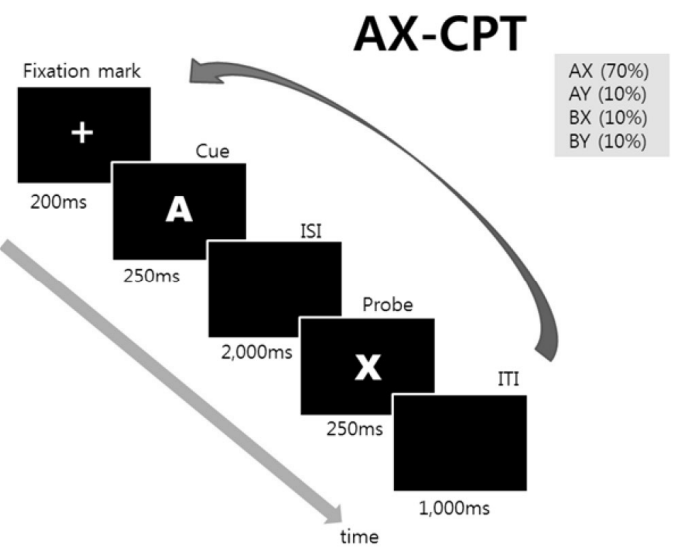

Figure 2. Four conditions (A-X, A-Y, B-X, B-Y) used in the AX-CPT paradigm (top) and the procedure of AX-CPT paradigm used in the experiment (bottom).

\subsubsection{ERP recording and analysis}

$32 \mathrm{Ag}-\mathrm{AgCl}$ channel electrodes were placed on a scalp using international 10-20 electrode system. The ground electrode was placed at AFz, 
the reference electrode was attached to the tip of the nose, and HEOG and VEOG were acquired horizontally and vertically from each eye. The data was amplified using the actiCHamp amplifier (Brain Products $\mathrm{GmbH}$, Munchen, Germany) with a sampling rate of $500 \mathrm{~Hz}$, and impedances were kept below $10 \mathrm{kG}$. An ocular correction was visually inspected, and those with excessive noise were removed from the data.

EEG data were analyzed using Brain Vision Analyzer 2.0 (Brain Products $\mathrm{GmbH}$, Munchen, Germany). A bandpass filter of 0.01 - 30 $\mathrm{Hz}$ was applied for the $\mathrm{P} 3 \mathrm{a}$ and $\mathrm{P} 3 \mathrm{~b}$ components with a slope of 12 $\mathrm{dB} /$ octave. N2 component was filtered separately, $2-12 \mathrm{~Hz}$, because of the tendency of being absorbed by following P3 component (Donkers et al. 2005). The data with amplitude $+/-100 \mu \mathrm{V}$ were excluded from the analysis and baseline was corrected $100 \mathrm{~ms}$ before the stimuli. Electrodes of $\mathrm{Fz}, \mathrm{Cz}, \mathrm{Pz}$ were used in the analysis since these are the main electrodes that the three ERP components are mainly found (Polich 2007; Rosenfeld 1993; Folstein \& Van Petten 2008). One participant from the learning group and five participants in the control group were excluded from the analysis because of the contaminated data and exceptional L1 language history.

\section{Results}

We performed a mixed repeated-measures ANOVAs for the learning group with electrodes $(\mathrm{Fz}, \mathrm{Cz}, \mathrm{Pz}) \times$ conditions (A-cue, B-cue $/ \mathrm{AX}$, $\mathrm{AY}, \mathrm{BX}, \mathrm{BY}) \times$ learning (before, after) as factors for all components, $\mathrm{P} 3 \mathrm{~b}$ (cue processing), $\mathrm{P} 3 \mathrm{a}$ and $\mathrm{N} 2$ (probe processing). We analyzed the data separately depending on the ERP components. In the case of P3b and P3a, 350-500 ms and 300-500 ms time windows were used respectively. The time window for the N2 component was $250-350 \mathrm{~ms}$. To exclude the possibility of practice effect due to the repeated paradigm, we separately performed the same analysis to control group as the learning group. The results of each ERP components in both learning and control groups are summarized in Table 2. 
Table 2. Statistics of the ERP Components in Learning and Control Groups

\begin{tabular}{|c|c|c|c|c|c|c|c|c|}
\hline \multirow[b]{2}{*}{ Components } & \multirow[b]{2}{*}{ Factors } & \multirow[b]{2}{*}{ Effects } & \multicolumn{3}{|c|}{ Learning group } & \multicolumn{3}{|c|}{ Control group } \\
\hline & & & $F$ & $p$ & sig & F & $p$ & sig \\
\hline \multirow[t]{7}{*}{$\mathrm{P} 3 \mathrm{~b}$} & $\begin{array}{l}\text { Electrodes }(\mathrm{Fz}, \mathrm{Cz}, \mathrm{Pz}) \times \text { Conditions }(\mathrm{A}-\mathrm{cue}, \mathrm{B}-\mathrm{cue}) \\
\times \text { Learning (before,after) }\end{array}$ & Electrodes & 4.329 & 0.022 & * & 0.531 & 0.596 & \\
\hline & & Conditions & 19.212 & $<.001$ & $* * *$ & 7.757 & 0.019 & * \\
\hline & & Learning & 4.043 & 0.063 & & 1.013 & 0.092 & \\
\hline & & Electrodes $\times$ Conditions & 14.342 & $<.001$ & $* * * G$ & 15.82 & $<.001$ & $* * *$ \\
\hline & & Electrodes $\times$ Learning & 2.219 & 0.145 & G & 0.531 & 0.596 & \\
\hline & & Conditions $\times$ Learning & 0.037 & 0.85 & & 3.337 & 0.098 & \\
\hline & & $\begin{array}{l}\text { Electrodes } \times \text { Conditions } \\
\times \text { Learning }\end{array}$ & 1.011 & 0.376 & & 0.239 & 0.79 & G \\
\hline \multirow[t]{7}{*}{ P3a } & $\begin{array}{l}\text { Electrodes }(\mathrm{Fz}, \mathrm{Cz}, \mathrm{Pz}) \times \text { Conditions }(\mathrm{A}-\mathrm{Y}, \mathrm{B}-\mathrm{X}) \\
\times \text { Learning }(\text { before, after })\end{array}$ & Electrodes & 13.275 & 0.002 & $* * \mathrm{G}$ & 4.102 & 0.032 & * \\
\hline & & Conditions & 16.835 & $<.001$ & $* * *$ & 4.072 & 0.033 & * \\
\hline & & Learning & 6.208 & 0.025 & * & 0.046 & 0.835 & \\
\hline & & Electrodes $\times$ Conditions & 25.693 & $<.001$ & $* * * \mathrm{G}$ & 2.361 & 0.069 & \\
\hline & & Electrodes $\times$ Learning & 4.343 & 0.046 & $* \mathrm{G}$ & 0.255 & 0.777 & \\
\hline & & Conditions $\times$ Learning & 0.148 & 0.863 & & 2.093 & 0.149 & \\
\hline & & $\begin{array}{l}\text { Electrodes } \times \text { Conditions } \\
\times \text { Learning }\end{array}$ & 1.589 & 0.189 & & 1.416 & 0.246 & \\
\hline \multirow[t]{7}{*}{ N2 } & $\begin{array}{l}\text { Electrodes }(\mathrm{Fz}, \mathrm{Cz}, \mathrm{Pz}) \times \text { Conditions }(\mathrm{A}-\mathrm{Y}, \mathrm{B}-\mathrm{X}) \\
\times \text { Learning }(\text { before, after })\end{array}$ & Electrodes & 67.554 & $<.001$ & $* * * G$ & 50.24 & $<.001$ & $* * * \mathrm{C}$ \\
\hline & & Conditions & 10.056 & $<.001$ & *** & 1.677 & 0.212 & \\
\hline & & Learning & 1.573 & 0.229 & & 0.811 & 0.389 & \\
\hline & & Electrodes $\times$ Conditions & 4.089 & 0.017 & $* * G$ & 3.117 & 0.025 & *G \\
\hline & & Electrodes $\times$ Learning & 2.448 & 0.124 & G & 0.437 & 0.534 & G \\
\hline & & Conditions $\times$ Learning & 0.178 & 0.838 & & 0.127 & 0.881 & \\
\hline & & $\begin{array}{l}\text { Electrodes } \times \text { Conditions } \\
\times \text { Learning }\end{array}$ & 1.443 & 0.231 & & 0.18 & 0.856 & G \\
\hline
\end{tabular}

* for $\mathrm{p}$-value $<0.05 ; * *$ for $\mathrm{p}$-value $<0.01 ; * * *$ for $\mathrm{p}$-value $<0.001$; $^{\mathrm{G}}$ for Greenhouse-Geisser corrected value.

\subsection{Proactive control component: $\mathrm{P} 3 \mathrm{~b}$}

We performed a mixed repeated-measures ANOVAs for Electrodes $(\mathrm{Fz}$, $\mathrm{Cz}, \mathrm{Pz}) \times$ Conditions (A-cue, B-cue) $\times$ Learning (before, after) as factors. The results showed the main effect of Conditions $(F(1,15)=19.212$, $\left.p=.001, \eta_{p}^{2}=.562\right)$, Electrodes $\left(F(2,30)=4.329, p=.022, \eta_{p}^{2}=.224\right)$, and an interaction between Conditions and Electrodes were also found with a Greenhouse-Geisser correction $(F(1.204,18.064)=14.342, p=.001$, $\left.\eta_{p}{ }^{2}=.489, \chi^{2}(2)=15.133, p=.001, \varepsilon=.602\right)$. However, the main effect of Learning $\left(F(1,15)=4.043, p=.063, \eta_{p}^{2}=.212\right)$, an interaction between Learning and Conditions $\left(F(1,15)=.037, p=.850, \eta_{p}^{2}=.002\right)$, Learning and Electrodes $\left(F(1.408,21.124)=2.219, p=.145, \eta_{p}^{2}=.129\right.$, 
$\chi^{2}(2)=7.631, p=.022, \varepsilon=.704$, Greenhouse-Geisser corrected), and an interaction among Learning, Conditions, and Electrodes $(F(2,30)=$ 1.011, $p=.376, \eta_{p}^{2}=.063$ ) were not statistically significant. Subsequent analysis showed that $\mathrm{P} 3 \mathrm{~b}$ amplitude of B-cue condition was larger than of A-cue condition $(p<.001)$ (Figure 3$)$.

To eliminate the possibility of a practice effect due to the repeated paradigm, the same analysis was performed to the control group. In the control group, the main effect of Conditions $(F(1,10)=7.757, p=.019$, $\left.\eta_{p}^{2}=.437\right)$ and an interaction between Conditions and Electrodes $(F(2,20)$ $\left.=15.820, p<.001, \eta_{p}^{2}=.613\right)$ were found, but Learning effect $(F(1,10)$ $\left.=1.013, p=.338, \eta_{p}^{2}=.092\right)$ and Learning and Conditions interaction $\left(F(1,10)=3.337, p=.098, \eta_{p}^{2}=.250\right)$ were not found. The main effect of Electrode $\left(F(2,20)=1.047, p=.369, \eta_{p}^{2}=.095\right)$, an interaction between Learning and Electrodes $\left(F(2,20)=.531, p=.596, \eta_{p}{ }^{2}=.050\right)$, and an interaction among Learning, Conditions, and Electrodes $(F(1.264,12.639)$ $=.239, p=.790, \eta_{p}^{2}=.023, \chi^{2}(2)=7.858, p=.020, \varepsilon=.632$, Greenhouse-Geisser corrected) were not found. Subsequent analysis revealed that the peak of B-cue condition was significantly larger than the peak of A-cue condition $(p=.012)$.
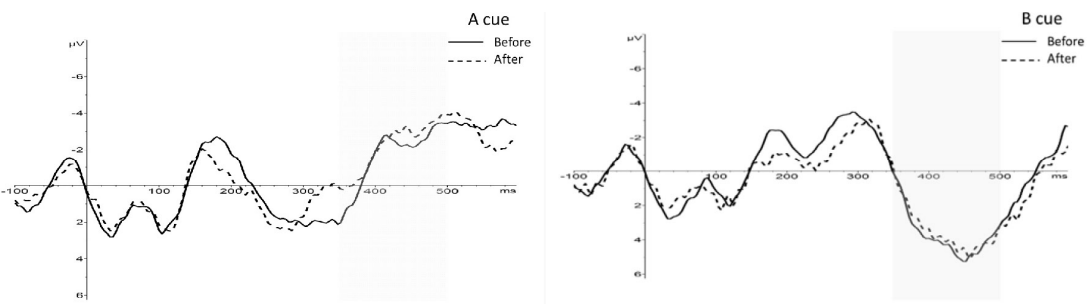

Figure 3. Grand averaged P3b from A-cue and B-cue conditions for before (black lines) and after (dotted lines) the third language learning within a time window of $350-500 \mathrm{~ms}$ at $\mathrm{Pz}$.

\subsection{Reactive control components: $\mathrm{P} 3 \mathrm{a}, \mathrm{N} 2$}

We conducted a repeated-measures ANOVAs for Electrodes $(\mathrm{Fz}, \mathrm{Cz}$, $\mathrm{Pz}) \times$ Conditions (AY, BX, BY) $\times$ Learning (before, after) as factors. We excluded AX condition due to the uneven stimuli number with other 
conditions for both P3a and N2 components referring to the previous study of Morales et al. (2015).

\subsection{1. $\mathrm{P} 3 \mathrm{a}$}

We performed a mixed repeated-measures ANOVAs for Electrodes $(\mathrm{Fz}$, $\mathrm{Cz}, \mathrm{Pz}) \times$ Conditions $(\mathrm{AY}, \mathrm{BX}, \mathrm{BY}) \times$ Learning (before, after) as factors. The results showed the main effects of Learning $(F(1,15)=6.208, p=$ $\left..025, \eta_{p}^{2}=.293\right)$, Conditions $\left(F(2,30)=16.835, p<.001, \eta_{p}{ }^{2}=.529\right)$, and Electrodes $\left(F(1.108,16.626)=13.275, p=.002, \eta_{p}^{2}=.470, \chi^{2}(2)\right.$ $=22.844, p<.001, \varepsilon=.554$, Greenhouse-Geisser corrected). Interactions between Conditions and Electrodes $(F(2.599,47.871)=25.693, p<.001$, $\left.\eta_{p}^{2}=.631, \chi^{2}(9)=18.243, p=.034, \varepsilon=.650\right)$, and Learning and Electrodes $\left(F(1.190,17.843)=4.343, p=.046, \eta_{p}^{2}=.225, \chi^{2}(2)=16.010, p<.001\right.$, $\varepsilon=.595)$ were found with a Greenhouse-Geisser correction. However, the interactions between Learning and Conditions $(F(2,30)=.148, p$ $\left.=.863, \eta_{p}^{2}=.010\right)$ and among Learning, Electrodes, and Conditions $(F$ $\left.(4,60)=1.589, p=.189, \eta_{p}^{2}=.096\right)$ were not statistically significant.

As we found that the $\mathrm{P} 3 \mathrm{a}$ component has the highest amplitude at $\mathrm{Cz}$, we conducted further analysis at the location of $\mathrm{Cz}$. The ANOVA with factors of Conditions (AY, BX, BY) $\times$ Learning (before, after) showed the main effects of Learning $\left(F(1,15)=9.863, p=.007, \eta_{p}^{2}=.397\right)$, Conditions $\left(F(2,30)=16.326, p<.001, \eta_{p}^{2}=.521\right)$, but Learning and Conditions interaction was not statistically significant $(F(2,30)=.244$, $\left.p=.785, \eta_{p}^{2}=.016\right)$. Among all conditions, AY condition has the highest amplitude than the other two conditions of BX and BY (all $p \mathrm{~s}<.010$ ), but the BY and BX conditions were not significantly different $(p=.785)$. On further analysis an increased amplitude in only the BX condition was found after learning $\left(F(1,15)=5.658, p=.031, \eta_{p}^{2}=.274\right)$, but not in AY $\left(F(1,15)=1.079, p=.315, \eta_{p}^{2}=.067\right)$ nor in BY $(F(1,15)$ $=2.051, p=.173, \eta_{p}^{2}=.120$ ) (Figure 4).

In the control group, Electrodes $\left(F(2,20)=4.102, p=.032, \eta_{p}^{2}=.291\right)$ and Conditions $\left(F(2,20)=4.072, p=.033, \eta_{p}^{2}=.289\right)$ main effects were found. However, no other main effects and interactions were significant (Learning $\left(F(1,10)=.046, p=.835, \eta_{p}^{2}=.005\right)$; Learning and 
Electrodes $\left(F(2,20)=.255, p=.777, \eta_{p}^{2}=.025\right)$; Learning and Conditions $\left(F(2,20)=2.093, p=.149, \eta_{p}^{2}=.173\right) ;$ Conditions and Electrodes $(F$ $\left.(4,40)=2.361, p=.069, \eta_{p}^{2}=.191\right)$; Learning, Electrodes, and Conditions $\left.\left(F(4,40)=1.416, p=.246, \eta_{p}^{2}=.124\right)\right)$. Subsequent analysis showed that a peak in AY condition was the largest as compared to the other conditions $(p=.036)$.

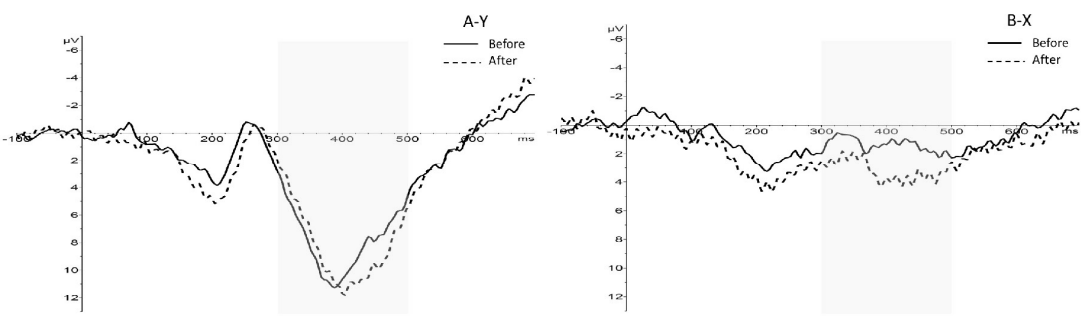

Figure 4. Grand averaged $\mathrm{P} 3 \mathrm{a}$ from $\mathrm{A}-\mathrm{Y}$ and $\mathrm{B}-\mathrm{X}$ conditions for before (black lines) and after (dotted lines) the third language learning within a time window of $300-500 \mathrm{~ms}$ at $\mathrm{Cz}$.

\subsection{2. $\mathrm{N} 2$}

A mixed repeated-measures ANOVAs for Electrodes $(\mathrm{Fz}, \mathrm{Cz}, \mathrm{Pz}) \times$ Conditions (AY, BX, BY) $\times$ Learning (before, after) was performed. The main effect of Conditions $\left(F(2,30)=10.056, p<.001, \eta_{p}^{2}=.401\right)$, Electrodes $\left(F(1.296,19.444)=67.554, p<.001, \eta_{p}^{2}=.818, \chi^{2}(2)=\right.$ $10.959, p=.004, \varepsilon=.648$, Greenhouse-Geisser corrected), and an interaction between Electrodes and Conditions $(F(2.556,38.343)=4.089, p$ $=.017, \eta_{p}^{2}=.214, \chi^{2}(9)=26.142, p=.002, \varepsilon=.639$, Greenhouse-Geisser corrected) were found. However, the main effect of Learning $(F(1,15)$ $\left.=1.573, p=.229, \eta_{p}^{2}=.095\right)$, an interaction between Learning and Conditions $\left(F(2,30)=.178, p=.838, \eta_{p}^{2}=.012\right)$, Learning and Electrodes $\left(F(1395,20.924)=2.448, p=.124, \eta_{p}^{2}=.140, \chi^{2}(2)=7.963, p=.019\right.$, $\varepsilon=.697$, Greenhouse-Geisser corrected), and an interaction among Learning, Conditions, and Electrodes $\left(F(4,60)=1.443, p=.231, \eta_{p}^{2}\right.$ $=.088$ ) were not statistically significant (Figure 5).

In the control group, the main effect of Electrodes $(F(1.296,12.917)$ $\left.=50.240, p<.001, \eta_{p}^{2}=.834, \chi^{2}(2)=7.152, p=.028, \varepsilon=.646\right)$ and 
an interaction between Electrodes and Conditions $(F(2.310,23.096)=$ 3.117, $p=.025, \eta_{p}^{2}=.238, \chi^{2}(9)=20.839, p=.015, \varepsilon=.577$, Greenhouse-Geisser corrected) were found. No other main effects or interactions were statistically significant (Learning $(F(1,10)=.811, p=.389$, $\left.\eta_{p}^{2}=.075\right)$; Conditions $\left(F(2,20)=1.677, p=.212, \eta_{p}^{2}=.144\right)$; interactions between Learning and Conditions $\left(F(2,20)=.127, p=.881, \eta_{p}^{2}=.013\right)$; Learning and Electrodes $\left(F(1.060,10.597)=.437, p=.534, \eta_{p}^{2}=.042\right.$, $\chi^{2}(2)=19.652, p<.001, \varepsilon=.530$, Greenhouse-Geisser corrected); and interaction among Learning, Electrodes, and Conditions $(F(2.203,22.033)$ $=.180, p=.856, \eta_{p}^{2}=.018, \chi^{2}(9)=18.231, p=.036, \varepsilon=.551$, Greenhouse-Geisser corrected).
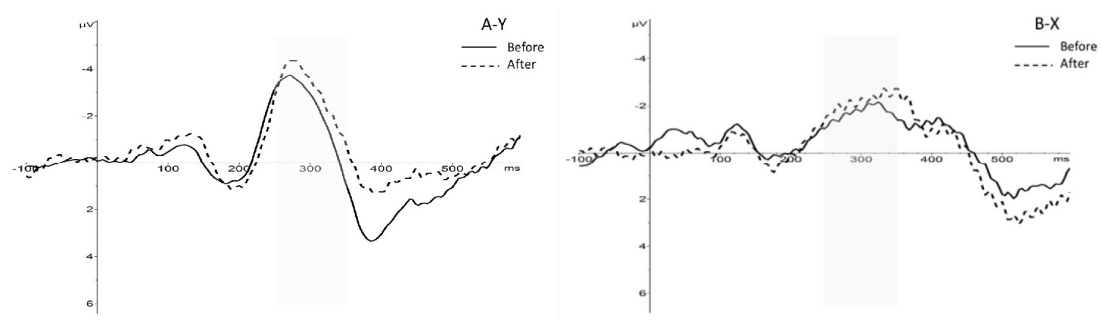

Figure 5. Grand averaged N2 from A-Y and B-X conditions for before (black lines) and after (dotted lines) the third language learning within a time window of $250-350 \mathrm{~ms}$ at $\mathrm{Fz}$.

Table 3. A Summary Table for the Results of ERP Components

\begin{tabular}{cccc}
\hline & proactive control & \multicolumn{2}{c}{ reactive control } \\
\hline & $\mathrm{P} 3 \mathrm{~b}$ & $\mathrm{P} 3 \mathrm{a}$ & $\mathrm{N} 2$ \\
\hline \hline learning group & no difference & larger $\mathrm{B}-\mathrm{X}$ & no difference \\
\hline control group & no difference & no difference & no difference \\
\hline
\end{tabular}

\section{Discussion}

The goal of the present study was to evaluate if the third language acquisition brings changes in our cognitive functions. For this aim, we used AX-CPT paradigm while recording ERP activity to demonstrate neu- 
ral responses in both proactive and reactive controls. By comparing before and after the language training, we suggest a direct influence of the third language acquisition in terms of the executive function.

In proactive control processing, $\mathrm{P} 3 \mathrm{~b}$ on $\mathrm{B}$-cue condition had a larger amplitude than the A-cue condition in both before and after the language training. This difference between two cue conditions has been observed in many previous studies as an evidence of using proactive processing in the AX-CPT paradigm (Morales et al. 2015; Zhang et al. 2015; Kam et al. 2012). Therefore, these results of our experiment confirm that the proactive processing is properly engaged in the paradigm. However, we could not find the main effect of learning, that is P3b did not change after the third language acquisition. This result is in the same line with the earlier study by Morales et al. (2015) which also found the result that bilinguals and monolinguals did not differ in P3b amplitude in both A-cue and B-cue conditions. Although they compared bilinguals to monolinguals, while we compared before and after bilinguals learned the third language, we may suggest that the additional language to the mother tongue does not affect to a cognitive control of activating a goal. According to Abutalebi and Green (2008), three elements are engaged in bilinguals' language processing; facilitating, suppressing, and monitoring. Since multilinguals need to manipulate their languages, they have to facilitate a target language while suppressing their other languages not in use, and monitor their language because of the language processing characteristic of parallel activation. Previous studies have found that proactive control is better in bilinguals compared to the monolinguals (Morales et al. 2013; Zhang et at. 2015). However, our result revealed that the proactive control which is a goal activation does not affect by learning an additional language to the second language. This result may be due to the low proficiency and relatively short exposure to the third language, but further studies are needed to make this assumption.

In reactive control processing, we also found the larger $\mathrm{P} 3 \mathrm{a}$ and $\mathrm{N} 2$ in A-Y than other conditions in line with the previous studies (Morales et al. 2015; Zhang et al. 2015; Kam et al. 2012; Lamm et al. 2013). This trend indicates that the participants used reactive control processing 
when they were performing the paradigm. The response inhibition function of the reactive processing showed an intriguing result. After the third language learning, the amplitude of $\mathrm{P} 3 \mathrm{a}$ increased in $\mathrm{B}-\mathrm{X}$ condition, while A-Y condition did not show any changes. This result can be explained by the different role in cognitive control processing of the two conditions. The A-Y condition requires reactive inhibition control which is needed to overcome the prepared proactive control. In contrast, the B-X condition is mainly processed using reactive inhibition control and less proactive control (Kam et al. 2012). Thus, we can assume that a reactive control without proactive processing can be improved by the newly learned L3, but a reactive control that includes proactive control is not affected by multilingual learning. The inhibition function in multilinguals can be further developed by the result of Morales et al. (2015). The result showed that bilinguals had larger P3a only in A-Y condition than monolinguals, indicating that bilinguals overcome the cue bias better when the probe was presented. Based on these results, we can predict that bilinguals are better at suppressing biased cue information using the probe stimuli than monolinguals, and when a bilingual individual becomes a third language learner, they inhibit the biased target probe after a non-target cue better than monolinguals. According to the DMC model, proactive and reactive controls have to interact with each other to successfully manage the given task demands (Braver 2007). As the number of using languages increases, proactive and reactive controls are in more demands and this resulted in a higher reactive control in our study. Both Morales et al. (2015) and our studies showed that the group with more languages showed higher reactive control but in different conditions, A-Y condition in bilinguals and $\mathrm{B}-\mathrm{X}$ condition in the third language learners. We need further studies to understand why and what causes these different results according to the number of languages.

Another reactive control ERP component N2 which represents conflict monitoring function did not change after the language learning across all conditions. Because the study by Morales et al. (2015) found larger $\mathrm{N} 2$ in the bilingual group than the monolingual group in A-Y condition, we assume that the early phase of language acquisition is not enough 
to change the conflict monitoring function.

In this study, the L3 proficiency was not considered because the aim of this study was to identify changes in executive function that occur when bilinguals, who had not yet learned L3, learned L3. It would be a more interesting analysis if L3 proficiency was measured and used to demonstrate an effect of L3 proficiency on executive functions. Unfortunately, in this study, the learning period was only six weeks; so it was not possible to measure the proficiency precisely. A subsequent study involving a longer learning period will lead to a more in-depth analysis of the impact of L3 on executive functions.

Language distance may be another factor to be taken into consideration for future study. The languages used in this study, English and German, are West Germanic languages that are close to each other in terms of the language distance. If the third language is far from the second language or if the third language is close to their L1 but far from the L2, these differences in language distance may demonstrate interesting results. For example, a previous study has compared native speakers of Spanish and native speakers of Basque to see which of the two groups has advantages on learning a second language, which was English (Cenoz 2001). The result found Spanish speakers had more advantages on learning English than the Basque speakers because Spanish is an Indo-European language like English, whereas Basque is not. We suggest that this cross-linguistic transfer phenomenon can affect not only language acquisition but nonlinguistic cognitive functions as well.

\section{Conclusion}

The purpose of this study was to investigate the multilingual effect of the third language acquisition on nonverbal cognitive function. In order to provide extensive data to the existing studies, which mainly compared bilinguals and monolinguals, we investigated whether the third language also brings changes in our executive functions. By comparing before and after the third language learning, our study provided a piece of evidence 
for a direct effect of third language acquisition on goal activation, conflict monitoring, and response inhibition. The ERP activity showed deteriorated goal activation but strengthened inhibition control after learning a third language. Our study provides novel and meaningful results on the nonverbal effect of multilingualism in the process of acquiring a third language and we expect that this study would effectively contribute to building an integrated cognitive model of multilingualism.

\section{References}

Abutalebi, Jubin and David W. Green. (2008). Control mechanisms in bilingual language production: Neural evidence from language switching studies. Language and cognitive processes 23.4, 557-582.

Aronin, Larissa and David Singleton. (2008). Multilingualism as a new linguistic dispensation. International journal of multilingualism 5.1, 1-16.

Bialystok, Ellen. (2010). Bilingualism. Wiley interdisciplinary reviews: cognitive science 1.4, 559-572.

Bialystok, Ellen and Michelle M. Martin. (2004). Attention and inhibition in bilingual children: Evidence from the dimensional change card sort task. Developmental science 7.3, 325-339.

Braver, Todd S. (2012). The variable nature of cognitive control: a dual mechanisms framework. Trends in cognitive sciences 16.2, 106-113.

Braver, Todd S., Jeremy R. Gray, and Gregory C. Burgess. (2007). Explaining the many varieties of working memory variation: Dual mechanisms of cognitive control. Variation in working memory, 76-106.

Carter, Cameron S. and Vincent Van Veen. (2007). Anterior cingulate cortex and conflict detection: an update of theory and data. Cognitive, Affective, \& Behavioral Neuroscience 7.4, 367-379.

Cenoz, Jasone. (2013). The influence of bilingualism on third language acquisition: Focus on multilingualism. Language Teaching 46.01, 71-86.

Dijkstra, Ton and Walter JB Van Heuven. (1998). The BIA model and bilingual word recognition. Localist connectionist approaches to human cognition, 189-225.

Donkers, Franc CL, Sander Nieuwenhuis, and Geert JM Van Boxtel. (2005). Mediofrontal negativities in the absence of responding. Cognitive brain research 25.3, 777-787.

Emmorey, Karen, Gigi Luk, Jennie E. Pyers, and Ellen Bialystok. (2008). The 
source of enhanced cognitive control in bilinguals: Evidence from bimodal bilinguals. Psychological Science 19.12, 1201-1206.

Falkenstein, Michael. (2006). Inhibition, conflict and the Nogo-N2. Clin Neurophysiol 117.8, 1638-1640.

Folstein, Jonathan R. and Cyma Van Petten. (2008). Influence of cognitive control and mismatch on the N2 component of the ERP: a review. Psychophysiology 45.1, 152-170.

Goldstein, Abraham, Kevin M. Spencer, and Emanuel Donchin. (2002). The influence of stimulus deviance and novelty on the P300 and novelty P3. Psychophysiology 39.6, 781-790.

Gollan, T. H. and J. F. Kroll. (2001). The cognitive neuropsychology of bilingualism. What deficits reveal about the human mind/brain: A handbook of cognitive neuropsychology, 321-345.

Gratton, Gabriele, Carla M. Bosco, Arthur F. Kramer, Michael GH Coles, Christopher D. Wickens, and Emanuel Donchin. (1990). Event-related brain potentials as indices of information extraction and response priming. Electroencephalography and clinical neurophysiology 75.5, 419-432.

Green, David W. (1998). Mental control of the bilingual lexico-semantic system. Bilingualism: Language and cognition 1.02, 67-81.

Guo, Taomei, Fengqin Liu, Bingle Chen, and Shengcao Li. (2013). Inhibition of non-target languages in multilingual word production: Evidence from Uighur-Chinese-English trilinguals. Acta psychologica 143.3, 277-283.

Hämmerer, Dorothea, Shu-Chen Li, Viktor Müller, and Ulman Lindenberger. (2010). An electrophysiological study of response conflict processing across the lifespan: assessing the roles of conflict monitoring, cue utilization, response anticipation, and response suppression. Neuropsychologia 48.11, 3305-3316.

Kam, Julia WY, Rachelle Dominelli, and Scott R. Carlson. (2012). Differential relationships between sub-traits of BIS-11 impulsivity and executive processes: An ERP study. International Journal of Psychophysiology 85.2, 174-187.

Kaushanskaya, Margarita and Viorica Marian. (2009). The bilingual advantage in novel word learning. Psychonomic Bulletin(14) Review 16.4, 705-710.

Kim, Albert and Lee Osterhout. (2005). The independence of combinatory semantic processing: Evidence from event-related potentials. Journal of Memory and Language 52.2, 205-225.

Kuipers, Jan Rouke, Anastasia Uminski, Zoe Green, David Hughes, and Tommaso Aglietti. (2017). Word meaning acquisition is reflected in brain potentials of isolated words. Scientific Reports, 7.

Lamm, C., D. S. Pine, and N. A. Fox. (2013). Impact of negative affectively 
charged stimuli and response style on cognitive-control-related neural activation: an ERP study. Brain and cognition 83.2, 234-243.

Levy, Benjamin J., Nathan D. McVeigh, Alejandra Marful, and Michael C. Anderson. (2007). Inhibiting your native language the role of Retrieval-induced forgetting during Second-language acquisition. Psychological Science 18.1, 29-34.

Li, Ping, Sara Sepanski, and Xiaowei Zhao. (2006). Language history questionnaire: A web-based interface for bilingual research. Behavior research methods 38.2, 202-210.

Mackey, William F. (1987). Bilingualism and multilingualism. Soziolinguistik/ Sociolinguistics 1, 699-713.

Martin-Rhee, Michelle M., and Ellen Bialystok. (2008). The development of two types of inhibitory control in monolingual and bilingual children. Bilingualism: language and cognition 11.01, 81-93.

Mazza, Veronica, Massimo Turatto, and Alfonso Caramazza. (2009). An electrophysiological assessment of distractor suppression in visual search tasks. Psychophysiology 46.4, 771-775.

Meuter, Renata FI and Alan Allport. (1999). Bilingual language switching in naming: Asymmetrical costs of language selection. Journal of memory and language 40.1, 25-40.

Miyake, Akira, Naomi P. Friedman, Michael J. Emerson, Alexander H. Witzki, Amy Howerter, and Tor D. Wager. (2000). The unity and diversity of executive functions and their contributions to complex "frontal lobe" tasks: A latent variable analysis. Cognitive psychology 41.1, 49-100.

Morales, Julia, Carlos J. Gómez-Ariza, and M. Teresa Bajo. (2013). Dual mechanisms of cognitive control in bilinguals and monolinguals. Journal of Cognitive Psychology 25.5, 531-546.

Morales, Julia, Carolina Yudes, Carlos J. Gómez-Ariza, and M. Teresa Bajo. (2015). Bilingualism modulates dual mechanisms of cognitive control: Evidence from ERPs. Neuropsychologia 66, 157-169.

Moreno, Sylvain, Ellen Bialystok, Zofia Wodniecka, and Claude Alain. (2010). Conflict resolution in sentence processing by bilinguals. Journal of Neurolinguistics 23.6, 564-579.

Näätänen, Risto, Elyse S. Sussman, Dean Salisbury, and Valerie L. Shafer. (2014). Mismatch negativity (MMN) as an index of cognitive dysfunction. Brain topography 27.4, 451-466.

Nieuwenhuis, Sander, Gary Aston-Jones, and Jonathan D. Cohen. (2005). Decision making, the P3, and the locus coeruleus- norepinephrine system. Psychological bulletin 131.4, 510. 
Poarch, Gregory J. and Janet G. van Hell. (2012). Executive functions and inhibitory control in multilingual children: Evidence from second-language learners, bilinguals, and trilinguals. Journal of experimental child psychology 113.4, 535-551.

Polich, John. (2003). Theoretical overview of P3a and P3b. Detection of Change (pp. 83-98). Springer US. (2007). Updating P300: an integrative theory of P3a and P3b. Clinical neurophysiology 118.10, 2128-2148.

Raven, Jean. (2003). Raven progressive matrices. In Handbook of nonverbal assessment (pp. 223-237). Springer US.

Rodriguez-Fornells, Antoni, Ulrike Kramer, Urbano Lorenzo-Seva, Julia Festman, and Thomas F. Münte. (2012). Self-assessment of individual differences in language switching. Bilingualism and cognitive control, 123.

Rosenfeld, J. Peter, Mary M. Johnson, and Jenny Koo. (1993). Ongoing ischemic pain as a workload indexed by P3 amplitude and latency in real-versus feignedpain conditions. Psychophysiology 30.3, 253-260.

Rubin, Hyla and Anne Turner. (1989). Linguistic awareness skills in grade one children in a French immersion setting. Reading and writing 1.1, 73-86.

Ruchkin, Daniel S., Howard L. Canoune, Ray Johnson, and Walter Ritter. (1995). Working memory and preparation elicit different patterns of slow wave event-related brain potentials. Psychophysiology 32.4, 399-410.

Schneider, Walter, Amy Eschman, and Anthony Zuccolotto. (2002). E-Prime: User's guide. Psychology Software Incorporated.

Spivey, Michael J. and Viorica Marian. (1999). Cross talk between native and second languages: Partial activation of an irrelevant lexicon. Psychological science 10.3, 281-284.

Sullivan, Margot D., Monika Janus, Sylvain Moreno, Lori Astheimer, and Ellen Bialystok. (2014). Early stage second-language learning improves executive control: Evidence from ERP. Brain and language 139, 84-98.

Valian, Virginia. (2015). Bilingualism and cognition. Bilingualism: Language and Cognition 18.01, 3-24.

Van Heuven, Walter JB, Ton Dijkstra, and Jonathan Grainger. (1998). Orthographic neighborhood effects in bilingual word recognition. Journal of memory and language 39.3, 458-483.

Van Veen, Vincent and Cameron S. Carter. (2002). The anterior cingulate as a conflict monitor: fMRI and ERP studies. Physiology \& behavior 77.4, 477-482.

van Wouwe, Nelleke C., Guido PH Band, and K. Richard Ridderinkhof. (2011). Positive affect modulates flexibility and evaluative control. Journal of Cognitive 
Neuroscience 23.3, 524-539.

Wright, Margaret J., Michelle Luciano, Narelle K. Hansell, Gina M. Geffen, Laurie B. Geffen, and Nicholas G. Martin. (2002). Genetic sources of covariation among P3 (00) and online performance variables in a delayed-response working memory task. Biological Psychology 61.1, 183-202.

Zhang, Haoyun, Chunyan Kang, Yanjing Wu, Fengyang Ma, and Taomei Guo. (2015). Improving proactive control with training on language switching in bilinguals. NeuroReport 26.6, 354-35.

Young Hye Kwon

Brain-Humanities Lab

Seoul National University/

Program of Brain and Cognitive engineering,

Korea Advanced Institute of Science and Technology,

291 Daehak-ro, Yuseong-gu, Daejeon, 34141, Korea

E-mail: younghye@kaist.ac.kr

Sung-Eun Lee

Brain-Humanities Lab/ Dept. of German Language and Literature

Seoul National University

1 Gwanak-ro, Gwanak-gu, Seoul 08826, Korea

E-mail: cristlo5@snu.ac.kr, bhlabsnu@gmail.com

Received: October 31, 2017

Revised version received: December 17, 2017

Accepted: December 25, 2017 
